

RESEARCH ARTICLE

\title{
IMPACT OF NUTRACEUTICAL STIRRED YOGHURT ON OSTEOPOROSES USING THE OVARIECTOMIZED FEMALE WISTER RAT.
}

\author{
Mounira M. Ahmed ${ }^{1}$, Magda Abd El Aziz ${ }^{1}$, Sobhy H. M. ${ }^{3}$, Azer W. $Z^{3}$ and El Nawawy M. A. ${ }^{2}$ \\ 1. Animal Production Res. Institute, Agric. Res. Center, Ministry of Agric. Egypt. \\ 2. Food science Dept., Fac. of Agric., Ain Shams University. \\ 3. Institute of African Research and Studies, Cairo University.
}

\section{Manuscript Info}

Manuscript History

Received: 13 May 2017

Final Accepted: 15 June 2017

Published: July 2017

Key words:-

Stirred yoghurt, Oats, female Wister rats, OVX, Fosamax, Calcium, phosphorus,

Alkaline phosphatase, bone mineral

density, osteoporosis .

\section{Abstract}

The present study was conducted to evaluate the effect of using natural stirred yoghurt (A), stirred yoghurt fortified with oats $(5 \%)$ and mango (15\%) (B) and stirred yoghurt fortified with calcium silicate and mango $(\mathrm{C})$ on ovariectomy $(\mathrm{OVX})$ rats.

Female Wister rats aged 8-10 weeks were divided into three groups: healthy (control), OVX, and OVX with therapy (1 ml Fosamax drug).

Each group subdivided into four groups; three groups treated with oral administration of $7 \mathrm{ml}$ stirred yoghurt (A), (B) ,(C) and compared with untreated groups for five weeks experimental period. Serum calcium (Ca), phosphorous (P), alkaline phosphatase (ALP) and bone mineral density (BMD) were measured.

The results revealed that no significant difference in serum $\mathrm{Ca}, \mathrm{P}$ and ALP of healthy group with administration of stirred yoghurt treatments. Also, data showed that no significant change in $\mathrm{Ca}$ and $\mathrm{P}$ concentration of OVX rats, while very highly significant decreasing in serum ALP and BMD compared with healthy group. It was found that Fosamax drug decreased significant ALP activity and increased BMD in OVX group. Similar results were observed with administration of stirred yoghurt (A), (B) and (C).

The improvements of BMD in OVX groups treated with A, B and C were significantly high compared with OVX treated with Fosamax alone. However, it was found that BMD in OVX treated with B and C yoghurt was the highest compared with $\mathrm{A}$. It concluded that fortified stirred yoghurt $(\mathrm{A}, \mathrm{B}, \mathrm{C})$ may be contribute in preventing osteoporosis disease. While, fortified stirred yoghurt (B) and (C) enhanced the results with the best result in treatment (B).

Copy Right, IJAR, 2017,. All rights reserved.

\section{Introduction:-}

Nutraceutical foods to prevent chronic diseases are one of this century's key global challenges. These foods are thought to provide health benefits beyond basic nutrition and may play a role in reducing or minimizing the risk of some diseases (Takachi et al., 2008). According to the World Health Organization and the Food and Agriculture Organization, several dietary patterns along with lifestyle habits constitute major modifiable risk factors in relation to the development of coronary heart disease, cancer, type 2 diabetes, obesity, osteoporosis and periodontal disease 
(WHO, 2003). The increasing demand on such foods can be explained by the increasing cost of healthcare, the steady increase in life expectancy and the desire of older people for improved quality of their later years (Roberfroid, 2007).

The major bone disease is osteoporosis. It is a disease characteristic by a decrease in bone mass and a deterioration in bone micro architecture leads to an increased fragility of the skeleton, and therefore to a greater risk of fracture (Imai et al., 2009). Fractures are an important cause of morbidity and mortality among elderly patients with osteoporosis (Maruotti et al., 2011).

With ageing, there is a gradual loss of bone, with an accelerated loss apparent around the perimenopausal period in women. The main cause of osteoporosis is menopause or estrogen-deficiency (Shuid et al., 2011). Estrogen deficiency at menopause requires antiresorptive therapies. Therapies that significantly decrease the levels of boneturnover markers and increase bone mineral density (BMD) greatly reduce the risk of non vertebral fractures (Popp et al., 2014). Although Estrogen replacement therapy reduces the incidence of fracture and prevents bone loss. Recent studies suggest that long periods of treatment with estrogen are discouraged because of the possibility of malignant effects on the reproductive tissues, including the mammary glands (Basha et al., 2013).

Alendronate (Fosamax) belongs to a class of drugs known as bisphosphonates, it is most widely used for the prevention and treatment of osteoporosis. It is a type of anti-resorptive agent that reduces the risk of fractures by changing bone turnover and bone mineral density. Fosamax increased bone mineral density and cortical bone thickness, and decreased osteoblast activity slight (Black et al., 2006), but side effects may include abdominal pain and heartburn, recent evidence has suggested a possible increase in the incidence of oesophageal cancer with use of oral bisphosphonates (McGreevy and Williams, 2011).

In addition, modifications of lifestyle, no alcohol, no smoke, balanced diet, are highly recommended in patients with osteoporosis ( Cosman, et al., 2014). Indeed, nutritional factors are particular importance to bone health and they are modifiable by providing food-based recommendations. Yoghurt is widely consumed as functional food because of its high digestibility, bioavailability, and proteolytic activities (Shaboo and Ahmad, 2011). Fortified yoghurt with a variety of different nutritious components impact on preventing or treating some important diseases (Gahruie et al. 2015).

Cereal as oats and fruit as mango are rich source of soluble non digestable fiber, antoxidants and microelements. Some of these microelements are silicon, manganese and zinc. Therefore, the previous study used oats and mango as natural source to produce nutraceutical fortified yoghurt with increased microelements (Ahmad et al., 2017). Thus present study aimed to evaluate the effect of using nutraceutical stirred yoghurt fortified with oats and mango or fortified with calcium silicate and mango on osteoporosis ovariectomized rat.

\section{Materials and Methods:-}

Stirred yoghurt:-

Natural stirred yogurt (A), fortified stirred yoghurt with 5\% oats and $15 \%$ mango (B) fortified stirred yoghurt with calcium silicate $(0.03 \%)$ and $15 \%$ mango (C) were prepared according to Ahmad et al., 2017

\section{Animal, Housing and Diet:-}

Forty eight female Wister rats of 8 - 10 weeks old weighting about $150 \pm 10 \mathrm{~g}$ were obtained from the Institute of Ophthalmology Research, Giza, Egypt. The animals groups were placed in a cage at in an atmosphere of filtered, pathogen-free air and water and maintained at a room temperature $\left(20-25^{\circ} \mathrm{C}\right)$ with a $12 \mathrm{~h}$ and light cycle $(8-20 \mathrm{~h})$ and relative humidity of $50 \%$. The animals acclimatized for one week as an adaptation period.

The ovariectomized rat model induces bone loss:-

Ovariectomy surgery procedure:-

Bilateral ovariectomy (middle incision surgery) was performed for 32 female rats under anesthetized with a ketamine/xylazine (50 and $20 \mathrm{mg} / \mathrm{Kg}$ body weight, respectively).

Feeding: Normal diet (free from soy bean) (D)

Administration of stirred yoghurt (A, B, C) for rats: $400 \mathrm{~g}$ of stirred yoghurt $\times 0.018=7.2 \mathrm{~g}$

Drug treatment: Fosmax (alendronate) is used to treat and prevent osteoporosis. 
Fosmax dose administrated for ovariectomy group rats: $70 \mathrm{mg} \times 0.018=1.26 \mathrm{mg}$

The ovariectomized rat Design:-

The animal's models were divided into three main groups each groups divided to 4 subgroups of four rats of each.

The first groups of healthy rats (control):-

Group $_{1}$ was fed on normal diet (D)

Group $_{2}$ was fed on standard diet with $7 \mathrm{ml}$ stirred yoghurt (A) oral administration by pi-gastric tube

Group $_{3}$ was fed on standard diet with $7 \mathrm{ml}$ fortified stirred yoghurt with oats and mango (B) oral administration by epi-gastric tube.

Group $_{4}$ was fed on normal diet with $7 \mathrm{ml}$ fortified stirred yoghurt with calcium silicate oral administration by epigastric tube.

Second group of ovariectomy $(\mathrm{OVX})$ rats:-

Group $_{5}$ was fed on normal diet (D).

Group $_{6}$ was fed on normal diet with $7 \mathrm{ml}$ stirred yoghurt (A) oral administration

Group $_{7}$ was fed on normal diet with $7 \mathrm{ml}$ fortified stirred yoghurt with oats and mango (B) oral administration by epi-gastric tube.

Ggroup $_{8}$ was fed on normal diet with $7 \mathrm{ml}$ fortified stirred yoghurt with calcium silicate and mango (C) oral administration by epi-gastric tube.

Third group (OVX with therapy): -

All subgroups were injected with $1 \mathrm{ml}$ Fosamax (drug).

Group $_{9}$ was fed on normal diet (D).

Group $_{10}$ was fed on normal diet with7ml stirred yoghurt (A) oral administration by epi-gastric tube.

Group $_{11}$ was fed on normal diet with $7 \mathrm{ml}$ fortified stirred yoghurt with oats and mango (B) oral administration by epi-gastric tube.

Group $_{12}$ was fed on normal diet with $7 \mathrm{ml}$ fortified stirred yoghurt with calcium silicate and mango $\quad$ (C) oral administration by epi-gastric tube.

Body weight of experimental rats:-

Initial body weight and final body weight after the end of the experimental period (five weeks) was recorded and the percentage of weight gain was calculated.

Blood samples collections:-

All animals were fasted for $12 \mathrm{hrs}$, blood samples were collected without anticoagulant and allowed to clot, blood samples were centrifuged at $3000 \mathrm{x} \mathrm{g}$ for $10 \mathrm{~min}$ at $4^{\circ} \mathrm{C}$, to obtain clear serum. Serum was frozen at $-20^{\circ} \mathrm{C}$ until analyzed.

\section{Biochemical Analyses:-}

The clinical kits (Biodiagnostic, Egypt) were used for the determination of several parameters. Calcium and phosphorus contents in serum rats were measured according to (Gindler and King 1972 \& El-Merzabani et al. 1977), respectively. Serum alkaline phosphatase (ALP) was determined colorimetrically according to the method described by (Belfield and Goldberg 1971).

Measurement of bone mineral density (BMD):-

BMD of tibia with femur was determined was measured using dual-energy X-ray absorptiometry (DXA) ( Norland X R - 46 Rev. 4.5.0/2.3.1).

\section{Statistical Analyses:-}

All data were expressed as mean \pm SD. Statistical significance for data was determined using a one-way analysis of variance (ANOVA). The level of significance was accepted as $P<0.05$. 


\section{Results and Discussions:-}

Chemical composition of stirred yoghurt:-

Data in (Table 1) show the chemical composition and minerals in stirred yoghurt: natural (A), fortified with oats and mango ( B) fortified stirred yoghurt with calcium silicate and mango calcium(C) as reported by Ahmad et al., 2017, . Natural and fortified stirred yoghurt were characteristic by a free fat, high protein and macro elements as calcium, phosphorous and magnesium. Also data showed silicon level in treatments $\mathrm{B}$ and $\mathrm{C}$ was higher than treatment A. While manganese level in treatment B was higher than treatments (A) and (C). There were no highly variations in $\mathrm{Zn}$ content between treatments and control.

Table 1:- Chemical composition of the nutaceutical yoghurt

\begin{tabular}{|c|c|c|c|}
\hline \multirow{2}{*}{ Composition } & \multicolumn{3}{|c|}{ Treatments } \\
\cline { 2 - 4 } & $\mathrm{A}$ & $\mathrm{B}$ & $\mathrm{C}$ \\
\hline $\mathrm{pH}$ value & $4.48 \pm 0.01$ & $4.45 \pm 0.03$ & $4.22 \pm 0.01$ \\
\hline T.S \% & $13.01 \pm 0.01$ & $15.15 \pm 0.02$ & $15.38 \pm 0.04$ \\
\hline Protein \% & $5.42 \pm 0.05$ & $4.00 \pm 0.01$ & $4.85 \pm 0.03$ \\
\hline Fat \% & $0.15 \pm 0.02$ & $0.49 \pm 0.01$ & $0.26 \pm 0.03$ \\
\hline Ash \% & $1.08 \pm 0.02$ & $1.12 \pm 0.01$ & $1.17 \pm 0.01$ \\
\hline Fiber \% & - & $0.98 \pm 0.02$ & $0.35 \pm 0.02$ \\
\hline Carbohydrate \% & $6.26 \pm 0.02$ & $8.56 \pm 0.02$ & $8.26 \pm 0.02$ \\
\hline \multicolumn{3}{|c|}{ Minerals $(\mathrm{ppm}):$} \\
\hline $\mathrm{Ca}$ & $1704 \pm 10$ & $1453 \pm 9$ & $1833 \pm 15$ \\
\hline $\mathrm{P}$ & $1137 \pm 12$ & $923 \pm 5$ & $1133 \pm 4$ \\
\hline $\mathrm{Mg}$ & $218 \pm 3$ & $222 \pm 3$ & $35.62 \pm 0.10$ \\
\hline $\mathrm{Si}$ & $14.70 \pm 0.11$ & $35.40 \pm 0.02$ & $1.07 \pm 0.12$ \\
\hline $\mathrm{Mn}$ & $0.90 \pm 0.05$ & $4.60 \pm 0.03$ & $3.43 \pm 0.05$ \\
\hline $\mathrm{Zn}$ & $3.60 \pm 0.04$ & $3.42 \pm 0.03$ & \\
\hline
\end{tabular}

Percentage body weight gain of experimental rats:-

( Table 2) showed that percentage of weight gain in health group increased during the five weeks by $15 \%$. Percentage body weight gain in OVX groups was significantly more than the control group in all treatments. Moreover, it was observed the increase in percentage this percentage very highly increased affected by treatments (A, B, C).of body weight gain in all experimental groups' OVX rats in all treatments as shown in (Table 2). The percentage weight gain in all groups in treatment B was significantly lower than treatments (A) and (C).

Table 2:- Bodyweight gain (\%) of experimental female Wister rats

\begin{tabular}{|c|c|c|c|c|}
\hline \multirow{2}{*}{$\begin{array}{c}\text { Experimental groups } \\
\text { rats }\end{array}$} & \multicolumn{4}{|c|}{ Treatments } \\
\cline { 2 - 5 } & $\mathrm{D}$ & $\mathrm{A}$ & $\mathrm{B}$ & $\mathrm{C}$ \\
\hline Healthy & $15.13 \pm 2.13$ & $30.43 \pm 6.22$ & $18.75 \pm 3.36$ & $33.33 \pm 6.68$ \\
\hline OVX & $26.52 \pm 8.39$ & $35.09 \pm 7.40$ & $27.79 \pm 5.44$ & $41.67 \pm 9.58$ \\
\hline OVX with *therapy & $22.5 \pm 8.94$ & $31.00 \pm 8.76$ & $26.27 \pm 3.30$ & $31.67 \pm 2.46$ \\
\hline
\end{tabular}

- $D$ : normal diet.

- A: natural stirred yoghurt

- B: fortified stirred yoghurt with oats + mango

- C: fortified stirred yoghurt with calcium silicate + mango

- OVX: ovariectomized.

\section{The biochemical parameters:-}

Data regarding calcium concentration in serum rats are illustrated in (Table 3). The data obtained revealed that no significant increase in calcium level in serum of healthy group with administration of A, B and C treatments.

It was found that the calcium concentration increased in OVX rats. While, it decrease in treatments of OVX with Fosamax. These results indicated that Fosamax shows no significant decrease in calcium concentration in serum as well as with treatments $\mathrm{A}, \mathrm{B}$, and C. 
The phosphorous content in (Table 4) showed that no significant in phosphorous concentration recorded in OVX rats and OVX rats with Fosamax and stirred yoghurt treatments. Serum ALP levels were significantly increased in OVXrats compared to control group (Table 5). Fosamax decreased the ALP activity significantly in OVX group. Also similar results were observed in treatments (A, B, C). Although ALP levels were decreased in OVX with Fosamax and treatments $\mathrm{A}, \mathrm{B}$ and $\mathrm{C}$ in comparison to OVX rats. These levels remained significantly higher than the control group.

Table 3:- Calcium concentrations $(\mathrm{mg} / \mathrm{dl})$ in serum of experimental female Wister rats*

\begin{tabular}{|c|c|c|c|c|}
\hline Experimental groups & \multicolumn{4}{|c|}{ Treatments } \\
\cline { 2 - 5 } & $\mathrm{D}$ & $\mathrm{A}$ & $\mathrm{B}$ & $\mathrm{C}$ \\
\hline Healthy & $8.91 \pm 0.32$ & $9.38 \pm 0.21$ & $9.16 \pm 0.23$ & $9.25 \pm 0.25$ \\
\hline OVX & $9.56 \pm 0.94$ & $8.73 \pm 0.26$ & $8.47 \pm 0.92$ & $8.63 \pm 1.62$ \\
\hline OVX with *therapy & $9.22 \pm 0.79$ & $8.67 \pm 0.54$ & $8.42 \pm 0.46$ & $8.81 \pm 0.180$ \\
\hline
\end{tabular}

*For abbreviation see table 2

Table 4:- Phosphorus concentrations $(\mathrm{mg} / \mathrm{dl})$ in serum of experimental female Wister rats

\begin{tabular}{|c|c|c|c|c|}
\hline \multirow{2}{*}{$\begin{array}{c}\text { Experimental } \\
\text { groups }\end{array}$} & $\mathrm{D}$ & $\mathrm{A}$ & $\mathrm{B}$ & $\mathrm{C}$ \\
\cline { 2 - 5 } & $3.11 \pm 0.26$ & $3.08 \pm 0.28$ & $3.01 \pm 0.18$ & $3.07 \pm 0.21$ \\
\hline Healthy & $3.20 \pm 0.57$ & $3.16 \pm 0.42$ & $3.07 \pm 0.49$ & $3.14 \pm 0.48$ \\
\hline OVX & $2.95 \pm 0.54$ & $2.85 \pm 0.65$ & $2.75 \pm 0.68$ & $2.81 \pm 0.36$ \\
\hline $\begin{array}{c}\text { OVX with } \\
\text { *therapy }\end{array}$ & & & & \\
\hline
\end{tabular}

*For abbreviation see table 2

Table 5:- Alkaline phosphatase activity (IU/L) in serum of experimental female Wister rats.

\begin{tabular}{|c|c|c|c|c|}
\hline \multirow{2}{*}{$\begin{array}{c}\text { Experimental } \\
\text { groups }\end{array}$} & $\mathrm{D}$ & $\mathrm{A}$ & $\mathrm{B}$ & $\mathrm{C}$ \\
\cline { 2 - 5 } & $270.00 \pm 9.20$ & $261.47 \pm 7.30$ & $266.16 \pm 6.50$ & $261.25 \pm 8.40$ \\
\hline Healthy & $295.60 \pm 8.60$ & $286.33 \pm 9.70$ & $285.44 \pm 9.10$ & $283.22 \pm 7.30$ \\
\hline OVX & $286.83 \pm 9.16$ & $280.88 \pm 7.13$ & $278.49 \pm 6.02$ & $276.70 \pm 8.24$ \\
\hline $\begin{array}{c}\text { OVX with } \\
\text { therapy }\end{array}$ & & & \\
\hline
\end{tabular}

*For abbreviation see table 2

\section{Measurements of bone mineral density (BMD):-}

The data in (Table 6) showed the BMD in healthy group was $136.90 \mathrm{mg} / \mathrm{cm}^{2}$ and highly significant increased with treatments $\mathrm{A}, \mathrm{B}$, and $\mathrm{C}$. The maximum value with fortified stirred yoghurt with oats and mango (B) and minimum value with control stirred yoghurt (A). Also data indicated that BMD significant decreased in OVX group elevated with treatments $\mathrm{A}, \mathrm{B}$ and $\mathrm{C}$. The data indicated that treatment with fosamax increased bone minerals density in OVX rats.

These results were agreement with (McGreevy \& Williams, 2011). The improvements of BMD in OVX group with treatments $\mathrm{A}, \mathrm{B}$ and $\mathrm{C}$ were highly significant in comparison with Fosamax alone. On the other hand Fosamax with treatments $\mathrm{A}, \mathrm{B}$ and $\mathrm{C}$ groups gave higher BMD than that Fosamax alone.

Table 6:- Bone mineral density $\left(\mathrm{mg} / \mathrm{Cm}^{2}\right)$ of tibia plus femur in experimental female Wister rats

\begin{tabular}{|c|c|c|c|c|}
\hline \multirow{2}{*}{$\begin{array}{c}\text { Experimental } \\
\text { groups rats }\end{array}$} & $\mathrm{D}$ & $\mathrm{A}$ & $\mathrm{B}$ & $\mathrm{C}$ \\
\cline { 2 - 5 } & $136.90 \pm 2.80$ & $145.30 \pm 2.30$ & $152.20 \pm 2.14$ & $147.00 \pm 1.7$ \\
\hline Healthy & $122.00 \pm 3.39$ & $131.80 \pm 2.50$ & $139.10 \pm 2.40$ & $138.80 \pm 3.7$ \\
\hline OVX & $129.00 \pm 2.20$ & $133.80 \pm 3.20$ & $144.70 \pm 3.10$ & $140.20 \pm 2.80$ \\
\hline $\begin{array}{c}\text { OVX with } \\
\text { therapy }\end{array}$ & & & & \\
\hline
\end{tabular}

*For abbreviation see table $\mathbf{2}$ 
Quantitative measurements of bone mineral density (BMD) are essential for the clinical evaluation of patients with osteoporosis but, being a static parameter, provides no information of the rate of bone turnover (Ebeling \& Akesson, 2001).

\section{Conclusion:-}

It can be concluded that, the nutraceutical yoghurt is a safe product prevent osteoporosis, which can be attributed to its high content of macro elements as calcium, phosphorus and magnesium. Fortified stirred yoghurt with oats and mango; and calcium silicate and mango enhanced the effective on preventing osteoporosis with the best with oats treatment may be due to high content of both elements silicon and manganese.

\section{Acknowledgment:-}

I would like to thank all staff members of the Department of Dairy Chemistry and Institute of Ophthalmology Research.

\section{References:-}

1. Ahmad, M., M., Abd El aziz, M., Sobhy, H. ; Azer, W., Nawawy. M ., 2017. Fortification Stirred yogurt with some microelements using natural sources. Journal of food dairy sciences, Mansoura Univ., Vol. 8, (4), 169-172.

2. Basha, M.E.; Chang, S.; Burrows, L.J., 2013. Effect of estrogen on molecular and functional characteristics of the rodent vaginal muscularis. J Sex Med. 10:1219-1230.

3. Belfield, A., Goldberg, D., 1971|. Colorimetric determination of alkaline phosphatase activity. Enzyme 12: $561-566$.

4. Black, D.M., Schwartz, A.V, Ensrud, KE., 2006. Effects of continuing or stopping alendronate after 5 years of treatment: the Fracture Intervention Trial Long-term Extension (FLEX): a randomized trial. JAMA, 296: 2927-2938..

5. Cosman, F, de Beur, S. J., LeBoff, M. S., Lewiecki, E. M., Tanner, B., Randall, S. , Lindsay, R., 2014 . Clinician's Guide to Prevention and Treatment of Osteoporosis. Osteoporos Int. 25(10): 2359-2381.

6. Ebeling, P., Akesson, K. , 2001 . Role of biochemical markers in the management of osteoporosis. Best Pract Res Clin Rheumatol, 15, pp. 385- 400.

7. El-Merzabani, M.M., El-Aaser A.A., Zakhary N.I., 1977. A New method for Determination of inorganic phosphorus in serum Deproteinization. J. Clin. Chem. Clin. Biochem. 15: 715 - 718.

8. Gahruie,H.H., Eskandari, M.H. , Mesbahi, G. , Hanifpour, M.A., 2015. Scientific and technical aspects of yogurt fortification: food Science and Human Wellness 4, 1-8.

9. Ginder M., King, I.D., 1972. Chemical method for determination of calcium in serum. Am. J. Clin. Path. $58: 376$.

10. Imai, K, Ohnishi, I, Matsumoto, T., Yamamoto, S., Nakamura, K., 2009. Assessment of vertebral fracture risk and therapeutic effects of alendronate in postmenopausal women using a quantitative computed tomography-based nonlinear finite element method. Osteoporos Int. 20:801-810.

11. Maruotti, N., Grano,M; Colucci, S, D'onofrio, F, Cantatore, FP., 2011. Osteoclastogenesis and arthritis. Clin Exp Med.; 11:137-145.

12. McGreevy, C., Williams, D., 2011. Safety of drugs used in the treatment of osteoporosis. Ther Adv Drug Saf. Aug; 2(4): $159-172$.

13. Popp, A.W., Buffat, H., Cavelti, A., 2014. Cortical bone loss at the tibia in postmenopausal women with osteoporosis is associated with incident non-vertebral fractures: Results of a randomized controlled ancillary study of HORIZON. Maturitas. 2014; 77: 287-293.

14. Roberfroid, M. B., 2007. Concepts and strategy of functional food science: the European perspective. The American Journal of Clinical Nutrition, 71, 1660 - 1664. sativa L.) as a dual-purpose crop. Academic J. 9(4), 52-59.

15. Shaboo A., Ahmad, S. B., 2011. Changes in yoghurt fermentation characteristics, and antioxidant potential and in vitro inhibition of angiotensin-1converting enzyme upon the inclusion of peppermint, dill and basil. LWT-Food Sci. Technol.; 44:1458-1464.

16. Shuid, A.N.,Ping, L.L., Muhammad, N., Mohamed, N., Soelaiman, I.N., 2011. The effects of Labisiapumilavar.alata on bone markers and bone calcium in a rat model of post-menopausal osteoporosis. J Ethnopharmacol., 133 (2): 538 542 .

17. Takachi, R., Manami, I., Junko, I., Norie, K., Motoki, I., Shizuka, S., 2008. Fruit and vegetable intake and risk of total cancer and cardiovascular disease Japan public health center-based prospective study. American Journal of Epidemiology, 167(1), 59 - 70.

18. WHO, 2003. Diet, nutrition and the prevention of chronic diseases. WHO technical report series 916 . Geneva, Switzerland. 